\title{
Combined ToF-SIMS and XPS characterization of 304L surface after interaction with caesium iodide under PWR severe accident conditions
}

\author{
Dorel Obada ${ }^{1}$, Anne-Sophie Mamede ${ }^{2}$, Nicolas Nuns ${ }^{3}$, Anne-Cécile Grégoire ${ }^{1}$, Laurent \\ Gasnot $^{4}$
}

1 Institut de Radioprotection et de Sûreté Nucléaire, Pôle Sûreté Nucléaire, CEN Cadarache, Saint Paul lez Durance, F-13115, France; dorel.obada@irsn.fr ; annececile.gregoire@irsn.fr

2 Univ. Lille, CNRS, ENSCL, Centrale Lille, Univ. Artois, UMR 8181 - UCCS - Unité de Catalyse et Chimie du Solide, F-59000 Lille, France ; anne-sophie.mamede@ensc-lille.fr 3 Univ. Lille, CNRS, INRA, Centrale Lille, ENSCL, Univ. Artois, FR 2638 - IMEC Institut Michel-Eugène Chevreul, F-59000 Lille, France ; nicolas.nuns@univ-lille1.fr 4 Univ. Lille, CNRS, UMR 8522 - PC2A - Physicochimie des Processus de Combustion et de l'Atmopshère, F-59000 Lille, France ; laurent.gasnot@univ-lille1.fr

* Author to whom correspondence should be addressed; E-Mail: dorel.obada@irsn.fr

\begin{abstract}
In case of a severe accident (SA) occurring in a pressurized water reactor (PWR) fission products $(\mathrm{Cs}, \mathrm{I})$ are released from the degraded fuel and transported through the reactor coolant system (RCS). A part is deposited onto surfaces of the RCS and can be subsequently chemically re-mobilized, in case the atmosphere composition changes. In order to improve our understanding on the re-mobilization processes, it is important to describe the interactions between deposited fission products and surfaces representative of RCS in SA conditions (mainly oxidized SS 304L) and to identify the species formed after remobilization. In this
\end{abstract}


study CsI aerosols were deposited on the surface of 304L coupons, which have been previously oxidized. The deposits were afterwards re-heated (up to $750^{\circ} \mathrm{C}$ ) in either air or steam. At every step, the 304L coupons were analysed by a combination of surface analysis techniques (XPS, ToF-SIMS), Raman spectroscopy and SEM. It has been established that the initial surface state of the 304L coupons (i.e. oxidation in air or steam) has no effect on the release of caesium or iodine. However, the composition of the carrier gas during the reheating phase influences significantly the release of caesium. Specifically, in air a significant amount of Cs remains on the coupon and forms mixed oxides with chromium, such as $\mathrm{Cs}_{2} \mathrm{CrO}_{4}$ and $\mathrm{Cs}_{2} \mathrm{Cr}_{2} \mathrm{O}_{7}$. The results are then discussed and compared with literature data.

Keywords: Stainless steels ; XPS ; ToF-SIMS ; Severe accident ; Fission products ; Revaporisation

\section{Introduction}

In case of a severe nuclear accident occurring on a Pressurized Water Reactor (PWR), volatile fission products (FPs), such as caesium and iodine are released from the damaged fuel. They are transported through the reactor coolant system (RCS) and the containment building, and might be released into the environment by containment leakages, contributing to the radiological consequences for the population in the short term for iodine and long-term for caesium.

Most of the FPs, however, are deposited on the surface of the RCS [1] either by condensation or by thermophoresis (due to high thermal gradient), as well as by gravity deposition. The main pipes of the RCS are composed of AISI 304L and 316L austenitic stainless steel whereas the steam generator tubes are made of Inconel alloy. In the stringent conditions (high temperature, complex steam/hydrogen atmosphere) of a severe accident, such surfaces are 
significantly oxidized. The interactions of FPs with the RCS surface are a main issue in severe accident studies, since such interactions could play a role in delayed source term.

Previous studies [2-6] have already focused on the FPs-surface interaction, using a wide variety of analysis techniques (SEM-EDX, XPS, TEM, EPMA, XRF, Raman, XRD and SIMS). Particularly, Allen et al. [6] conducted a comprehensive multi-technique study of $\mathrm{CsOH}$ interaction with stainless steel at high temperature in presence of steam and hydrogen. The conclusion was that the diffusion of Cs through the oxide layer is temperature dependent. Also, at $750^{\circ} \mathrm{C}$ the oxide has a double-layer structure: a thin outer layer rich in $\mathrm{Fe}$ and an inner thick layer rich in $\mathrm{Cr}$.

Subsequent studies [1] [7] [8] have also shown that the FPs deposited on the RCS surface can be re-mobilized under certain conditions, particularly when the carrier gas composition changes. This work deals with the re-vaporisation of CsI aerosols deposits (natural isotopes) from pre-oxidized 304L stainless steel surface. The objectives were to address i) interactions with the stainless steel surface and ii) the nature of the revaporized species.

The 304L stainless steel is one the main materials used in the RCS piping (particularly the primary loop hot leg and cold leg) [9]. Special attention was brought to the substrate and its preparation in order to obtain a surface state as similar as possible of RCS inner parts after several hours of oxidation in steam conditions [12]. The reason is that during the normal operation of a PWR and especially during a severe accident, the surface of the RCS evolves as a result of the chemical and physical environment (high-temperature, high-pressure liquid water containing hydrogen, boric acid, lithium hydroxide and radioactive corrosion products) [13]. Particularly during a severe accident the fluid in the RCS is at high temperature, mainly in gas state and represents a mixture of $\mathrm{H}_{2} / \mathrm{H}_{2} \mathrm{O}$ and possibly even air, for air-ingress scenario [14]. The gas mixture depends on the accident type and the delayed time after the beginning of the accident. The composition and the structure of the oxide layers (iron (III) oxide in low- 
temperature oxidation conditions and chromium (III) oxide at higher temperatures) formed during a severe accident have been discussed by Mamede et al. [12].

Both Cs and I are FPs and CsI is one of the main species which is expected to be transported and deposited on the RCS surface during a SA transient [1]. Thus CsI could be a potential source for the release of gaseous iodine compounds ( $\mathrm{I}_{2}, \mathrm{HI}$, etc.). In this study, only CsI aerosols deposits were considered with amounts of about $1 \mathrm{mg} / \mathrm{cm}^{2}$, which is consistent with previous studies [10] [11].

The re-vaporisation tests were carried out at $750^{\circ} \mathrm{C}$, since Bottomley et al. [7] has observed that the re-vaporisation rate for $\mathrm{Cs}$ is greatly reduced above $800^{\circ} \mathrm{C}$. The carrier gas was either synthetic air or pure steam. While during a SA the atmosphere would be a mixture of steam, air and hydrogen, the choice of separate tests was done in order to study the impact of each gas components.

In the present study the surfaces before and after deposits re-vaporisation processes were carefully determined by advanced surface analysis characterization combining high resolution X-Ray Photoelectron Spectroscopy (XPS) and Time-of-Flight Secondary Ion Mass Spectrometry (ToF-SIMS). Additional analyses were carried by Scanning Electron Microscopy (SEM) and Raman Spectroscopy.

\section{Materials and methods}

\subsection{Pre-oxidation of 304L}

The 304L stainless steel coupons $(8 \times 15 \times 2 \mathrm{~mm})$, whose composition is presented in Table 1 , with surface roughness $\mathrm{Ra}$ of $0.8 \mu \mathrm{m}$ were cleaned in ethanol. Then they underwent a thermal treatment in a controlled atmosphere in a flow reactor to reproduce as close as possible the surface state of the RCS inner part in SA conditions. The thermal treatment consisted in exposing the coupons to a flow of either air or a mixture of argon/steam (v 50/50) at $750^{\circ} \mathrm{C}$ 
during $24 \mathrm{~h}$. The heating rate was $5^{\circ} \mathrm{C} / \mathrm{min}$ and steam was injected at $150^{\circ} \mathrm{C}$. The total gas flow rate was fixed at $1 \mathrm{~L} / \mathrm{min}$ at standard conditions.

\begin{tabular}{cccccccc}
\hline & $\mathrm{Fe}$ & $\mathrm{Cr}$ & $\mathrm{Ni}$ & $\mathrm{Mn}$ & $\mathrm{Si}$ & $\mathrm{C}$ & $\mathrm{P}, \mathrm{S}$ \\
\hline 304L SS & base & 18.21 & 8.02 & 1.64 & 0.46 & 0.02 & $<0.03$ \\
\hline
\end{tabular}

Table 1. Chemical composition of 304L alloy, in wt.\%

\subsection{CsI deposition}

CsI deposits were obtained by CsI aerosols impaction at room temperature on the oxidized coupons placed in an exposure cell connected to an aerosol generator (AGK 2000, Palas). Aerosols are generated by nebulization of a concentrated CsI aqueous solution $(240 \mathrm{~g} / \mathrm{L}$ of CsI powder $99.9 \%$, Acros Organics). The generated aerosols are then dried in a high argon flow $(10 \mathrm{~L} / \mathrm{min})$ and transported to the exposure cell where they are impacted on the coupons. About 3 hours of generation are necessary to achieve a deposition of a few $\mathrm{mg} / \mathrm{cm}^{2}$. The homogeneity of the aerosol deposition was checked so that up to eight coupons can be loaded per batch. The deposited mass is determined after leaching the coupons in alkaline media $(\mathrm{NaOH} 0.1 \mathrm{M})$ for $\mathrm{I}$ and $\mathrm{Cs}$ recovery in solution followed by elemental $\mathrm{I}$ and $\mathrm{Cs}$ determinations by Inductively-Coupled Plasma - Mass Spectrometry (ICP MS -Varian 810 MS).

\subsection{Vaporization of CsI deposits}

The vaporization of CsI deposits was monitored by thermogravimetric analysis (SETSYS EVO TGA instrument equipped with a type $\mathrm{P}$ thermocouple), allowing mass variation measurements with an accuracy of $+/-1 \mu \mathrm{g}$ during a thermal treatment (full mass variation range of $+/-20 \mathrm{mg})$ - after correction of buoyancy. A specific manufactured alumina tube (10 $\mathrm{mm}$ inner diameter) is inserted in the furnace chamber to protect it against corrosive deposition of Cs species. The samples are heated following a thermal cycle including a heating ramp (with a rate ranging from $1{ }^{\circ} \mathrm{C} / \mathrm{min}$ up to $10{ }^{\circ} \mathrm{C} / \mathrm{min}$ ), up to a temperature 
plateau $\left(750^{\circ} \mathrm{C}\right)$ which is maintained for 1 hour before cooling down by natural convection. During the thermal cycle, the sample is swept by a low carrier gas flow either composed of synthetic air $(30 \mathrm{~mL} / \mathrm{min})$ or steam/argon (steam mixture featuring a flow rate of $30 \mathrm{~mL} / \mathrm{min}$; argon flow rate set at $70 \mathrm{~mL} / \mathrm{min}$ ). Steam was injected at temperature above $150^{\circ} \mathrm{C}$ and switched off during the cooling phase (below $400^{\circ} \mathrm{C}$ ). After this thermal treatment, the residues (if any) on the coupons were analysed following the same procedure as for the initial deposited mass (see above).

\subsection{Surface characterization techniques}

The sample surface was characterized by combination of X-ray Photoelectron Spectroscopy (XPS) and Time-of-Flight Secondary Ion Mass Spectrometry (ToF-SIMS). XPS provides chemical composition of less than 10 nanometres depth scale of the surface while the ToFSIMS was used in depth profiling mode to reach composition up to several micrometres in depth. Several samples were also analysed by Raman spectroscopy. The morphology of the surface before and after re-vaporisation was investigated by Scanning Electron Microscopy (SEM).

XPS measurements were carried out on a Kratos AXIS Ultra ${ }^{\text {DLD }}$ spectrometer equipped with a monochromatic $\mathrm{Al} \mathrm{K} \alpha$ source $(1486.6 \mathrm{eV})$. The analyser was operated in constant pass energy of $40 \mathrm{eV}$ using an analysis area of approximately $700 \mu \mathrm{m} \times 300 \mu \mathrm{m}$. Calibration was done by using the $\mathrm{C} 1 \mathrm{~s}$ component of adventitious carbon at BE (binding energy) $=285.0 \mathrm{eV}$. Quantification and decomposition were carried out using CasaXPS software [15]. Quantification took into account a non-linear Shirley [16] background subtraction. Binding energy value uncertainty is $+/-0.1 \mathrm{eV}$ and uncertainty on quantitative elemental analysis is $+/$ $10 \%$.

ToF-SIMS analyses were carried out using a TOF.SIMS 5 instrument (IONTOF GmbH). Pulsed $\mathrm{Bi}_{1}{ }^{+}$primary ions have been used for analysis $(25 \mathrm{keV}, \approx 1 \mathrm{pA})$ and $\mathrm{O}_{2}{ }^{+}$for sputtering 
$(2 \mathrm{keV}, \approx 500 \mathrm{nA})$. While an oxidation of the metal is possible due to the use of an $\mathrm{O}_{2}^{+}$ sputtering ion beam, it has been estimated that the effect was not significant since the analysed surface has already been oxidized in severe conditions, at high temperature and for long duration. The sputtering rate was calculated taking into account the sputtering parameters such as sputter beam current, sputtered surface, the density of the material and the ionization yield at $45^{\circ}$ (data from the SurfaceLab software). For this calculation, the material was approximated as homogeneous chromium oxide $\mathrm{Cr}_{2} \mathrm{O}_{3}$. Given the sputter parameters, the sputter rate is estimated around $1.6 \mathrm{~nm} / \mathrm{s}$.

Mass spectra were recorded in positive polarity for each sample from an analysis area of $100 \mu \mathrm{m} \times 100 \mu \mathrm{m}$ centred into a $300 \mu \mathrm{m} \times 300 \mu \mathrm{m}$ sputtered area. Charging effects, due to analysis and sputtering ion beam, were compensated using low energy electrons $(20 \mathrm{eV})$. The secondary ions of interest are $\mathrm{Si}^{+},{ }^{53} \mathrm{Cr}^{+}, \mathrm{Mn}^{+}, \mathrm{Fe}^{+}$and $\mathrm{Cs}^{+}$. For all the elements, the signals of the most abundant natural isotopes are recorded, except for chromium. Since chromium oxide is the major phase formed on the surface, the ${ }^{52} \mathrm{Cr}^{+}$signal is saturated $\left({ }^{52} \mathrm{Cr}\right.$ being the most abundant isotope of natural chromium at $83.8 \%$ ), which makes the interpretation of the depth profile difficult. As a consequence, the ${ }^{53} \mathrm{Cr}^{+}$signal is recorded $\left({ }^{53} \mathrm{Cr}\right.$ being a less abundant isotope of natural chromium, $9.5 \%$ ).

Complementary Raman analyses were carried out using a Horiba Labram HR spectrometer equipped with a $\mathrm{Ar}^{+}(488 \mathrm{~nm})$ laser source and a long-distance objective (x50).

Scanning Electron Microscopy (SEM) images were obtained using a LEO-435 VP microscope. A $20 \mathrm{kV}$ accelerating voltage was used giving an interaction depth above 2.5 $\mu \mathrm{m}^{3}$

\section{Results and discussion}

\subsection{Oxidation of 304L}


The 304L stainless steel coupons were first thermal treated under air or a mixture of $\operatorname{argon} /$ steam (v 50/50) at $750^{\circ} \mathrm{C}$ during $24 \mathrm{~h}$. In order to investigate the chemical composition and the thickness of the oxide layer formed during the oxidizing treatment, depth profiles by ToF-SIMS (Figure 1) and XPS measurements were performed (Table 2 and Figure 2).
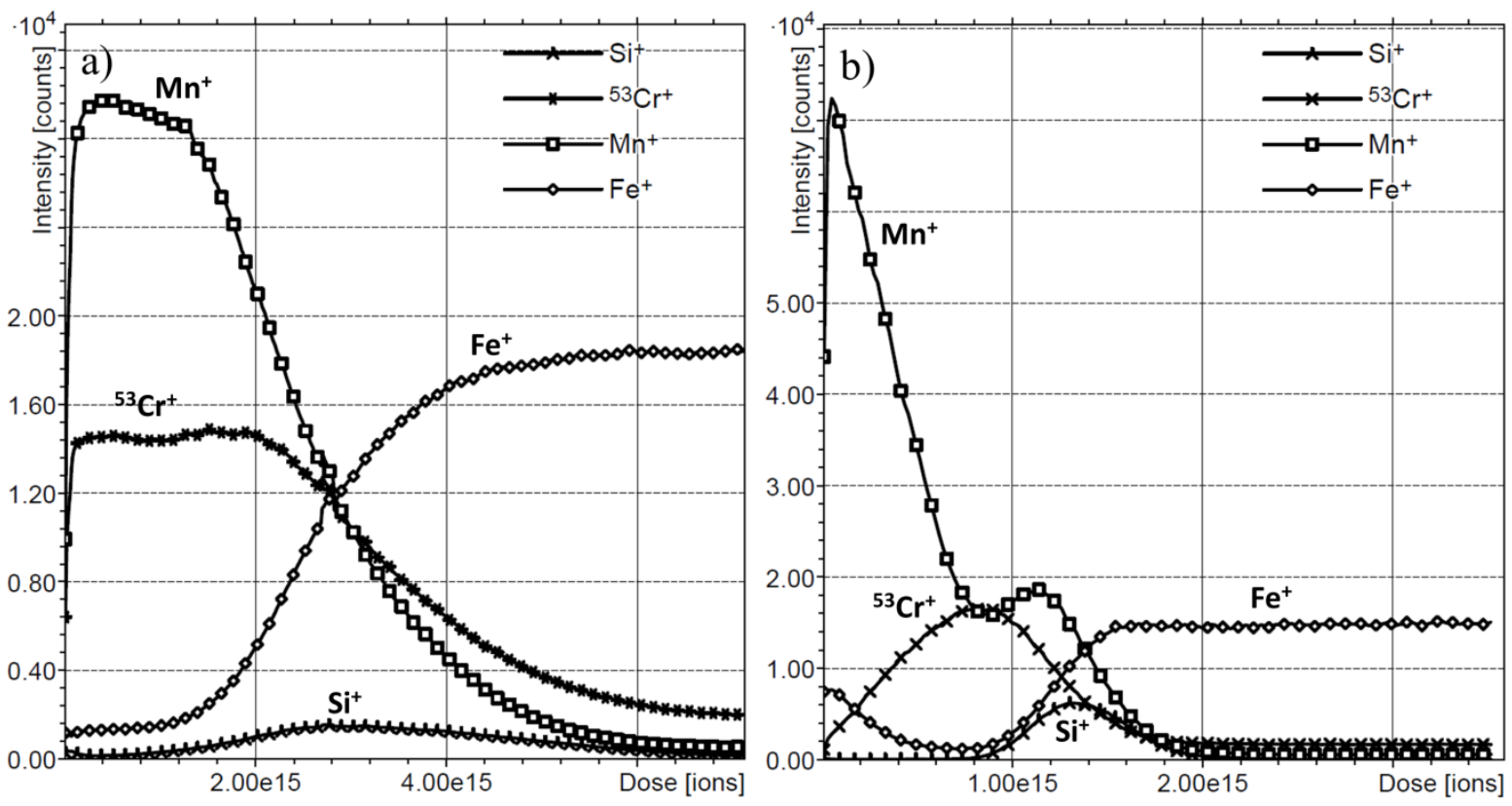

Figure 1: ToF-SIMS depth profiles of 304L oxidized at $750^{\circ} \mathrm{C}(24 \mathrm{~h})$ : a) under air and b) under steam atmospheres

The signal intensity of the secondary ions of $\mathrm{Fe}^{+},{ }^{53} \mathrm{Cr}^{+}$and $\mathrm{Mn}^{+}$have been recorded during profiling as they are the main elements expected from the chemical composition of 304L alloy (Table 1). It has to be mentioned that nickel is not shown as it was not detected in the formed oxide layer. Under air oxidation (Figure 1a), the oxide layer is mainly composed of a mixture of chromium and manganese, iron begins to be detected at the oxide layer/alloy interface and after in the bulk. The thickness of this oxide layer was estimated to around $1.7 \mu \mathrm{m}$. Under steam atmosphere (Figure 1b), the thickness of the oxide layer is lower, around $0.8 \mu \mathrm{m}$, and its composition and structure are significantly modified: at the outermost surface, a thinner layer only composed of manganese followed by a thicker layer composed of mainly 
chromium. These ToF-SIMS profiles directly show the influence of the oxidizing atmosphere on the thickness, structure and composition of the formed oxide layer.

In parallel, Table 2 summarises the surface composition determined from XPS measurements. After air oxidation, the surface composition exhibits an enrichment of chromium with a $\mathrm{Mn} / \mathrm{Cr}$ atomic ratio of 0.3 whereas after steam oxidation, the Mn enrichment of the outermost surface is confirmed with a $\mathrm{Mn} / \mathrm{Cr}$ atomic ratio of 10.6 , in agreement with the ToF-SIMS profiles.

\begin{tabular}{ccccccc}
\hline & \multicolumn{6}{c}{ XPS quantitative elemental composition (at. \%) } \\
\cline { 2 - 7 } & $\mathrm{Cr}$ & $\mathrm{Mn}$ & $\mathrm{Fe}$ & $\mathrm{O}$ & $\mathrm{C}$ & $\mathrm{Mn} / \mathrm{Cr}$ \\
\hline air & 17.8 & 5.4 & - & 53.1 & 23.7 & 0.3 \\
steam & 2.1 & 22.2 & 2.6 & 48.3 & 24.8 & 10.6 \\
\hline
\end{tabular}

Table 2: XPS quantitative elemental composition (atomic concentration \%) of the oxidized $304 \mathrm{~L}$ under air or steam at $750^{\circ} \mathrm{C}$ for $24 \mathrm{~h}$

Finally, XPS fitted representative high-resolution $\mathrm{Cr} 2 \mathrm{p}$ and Mn $2 p$ spectra are presented in Figure 2. Whatever the nature of the atmosphere, chromium is present $\mathrm{as} \mathrm{Cr}^{3+}$ in its oxide form as $\mathrm{Cr}_{2} \mathrm{O}_{3}$, as shown in Figure 2a. Indeed, the main component $\mathrm{Cr} 2 \mathrm{p}_{3 / 2}$ can be decomposed following the multiplet splitting of oxidic $\mathrm{Cr}^{3+}$ [12] [17]. Under steam atmosphere, the main component $\mathrm{Mn} 2 \mathrm{p}_{3 / 2}$ can be decomposed following the multiplet splittings of oxidic $\mathrm{Mn}^{2+}$ and $\mathrm{Mn}^{3+}$ [12] [17], indicating the presence of both $\mathrm{Mn}^{2+}$ and $\mathrm{Mn}^{3+}$ in their oxide forms as $\mathrm{MnO}$ and $\mathrm{Mn}_{2} \mathrm{O}_{3}$, respectively (Figure 2b) whereas under air atmosphere, manganese is only present as $\mathrm{Mn}^{2+}$ as $\mathrm{MnO}$. XPS reveals that exposure to steam atmosphere leads to a $\mathrm{Mn}$ enrichment of the surface, due to $\mathrm{Cr}$ evaporation $\left(\mathrm{CrO}_{2}(\mathrm{OH})_{2}\right.$ volatilisation), with a more effective oxidation of $\mathrm{Mn}$, in good agreement with our previous study [12]. 

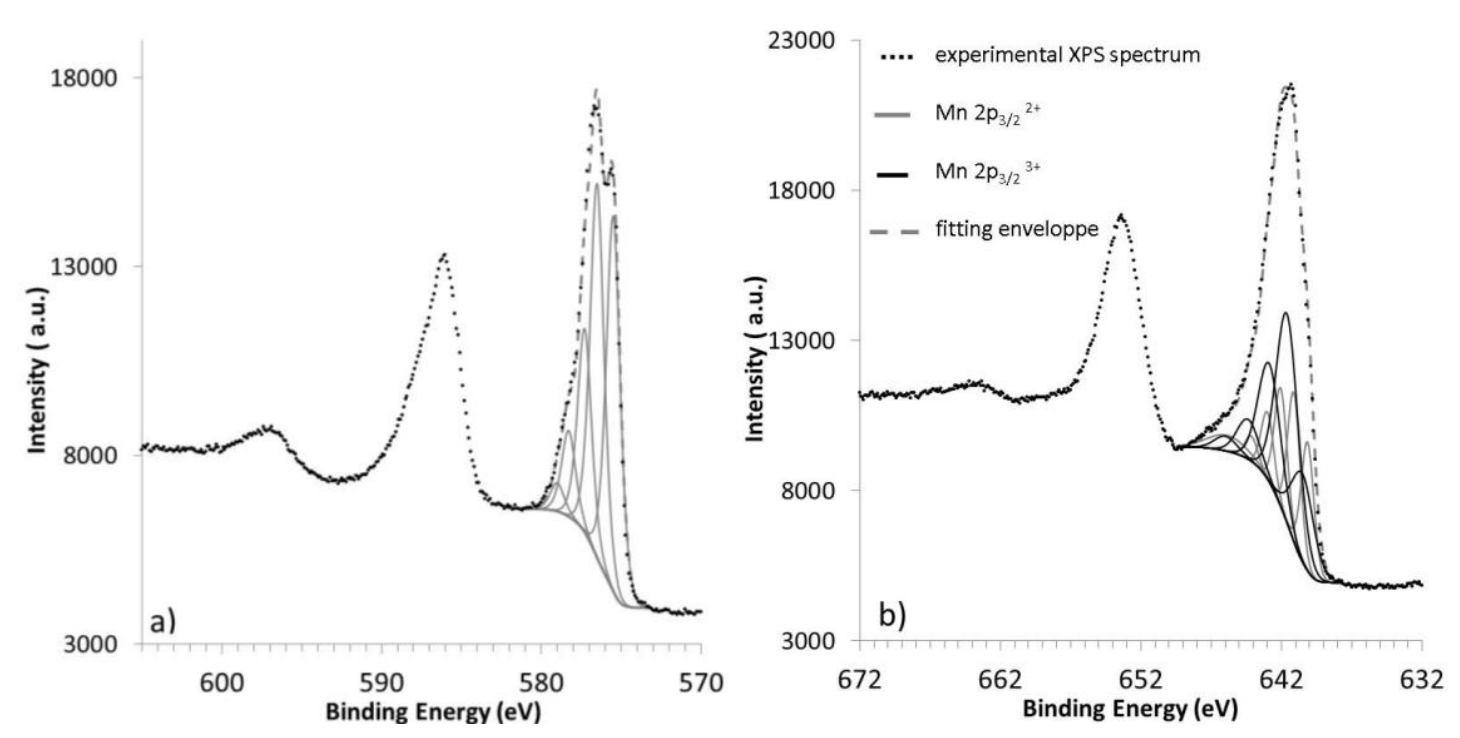

Figure 2: XPS spectra of 304L oxidized: a) Cr 2p under air atmosphere and b) Mn 2p under steam atmosphere

While iron is not detected on the surface after air oxidation, a low quantity of $\mathrm{Fe}^{3+}$ is detected after steam oxidation, suggesting that the oxide layer is non-uniform and is composed of manganese, chromium and iron oxides with some mixed oxides. Indeed, the sensitivity of ToF-SIMS allows the detection of iron at the outermost surface with manganese (Figure 1b), suggesting the presence of Fe-Mn mixed oxides or spinels that XPS cannot discriminate.

\subsection{CsI deposition}

After the pre-oxidation of 304L stainless steel surfaces, CsI is deposited by CsI aerosols impaction at room temperature. Size and morphology of CsI aerosols are characterised by SEM while the amount of deposited CsI is investigated by ICP-MS and XPS.

SEM images (Figure 3) reveal that the deposit is composed of micrometric particles with irregular shapes and of particle agglomerates with sizes from 5 to $20 \mu \mathrm{m}$ and with a cage structure (Figure 3a). At the interface with the alloy substrate (Figure 3b), an amorphous structure is observed, suggesting a partial hydration of CsI aerosols considering the hygroscopic character of CsI [18]. 

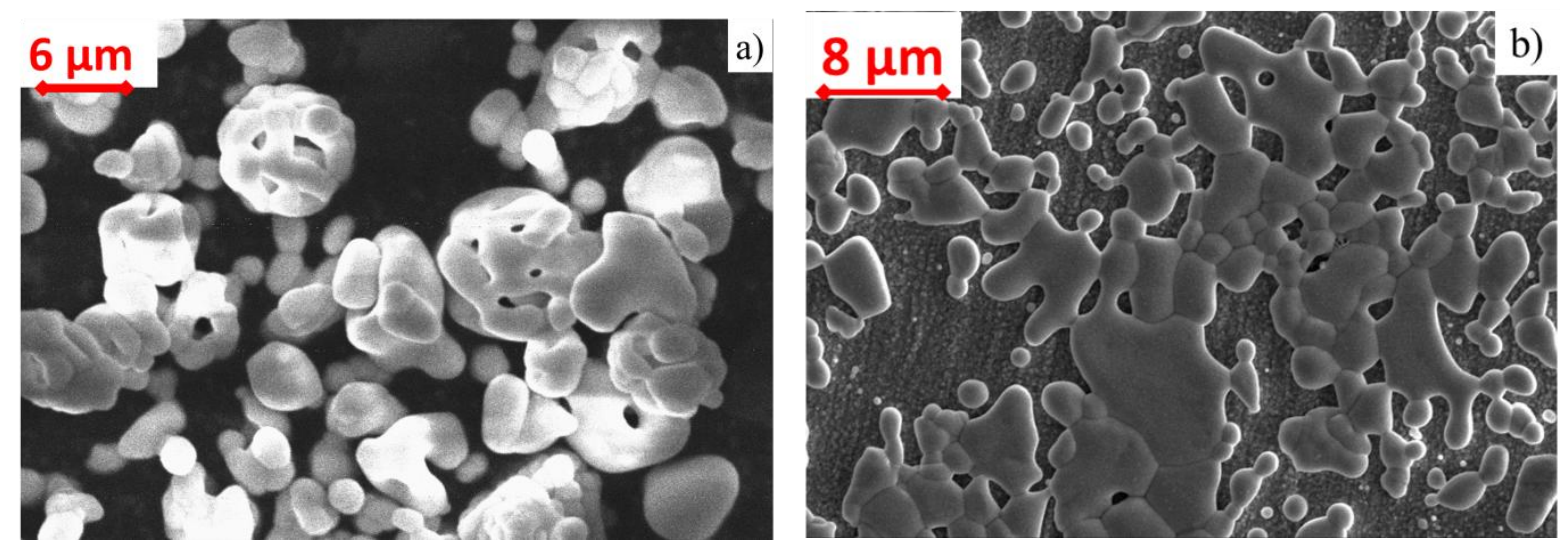

Figure 3: SEM images of CsI aerosols on pre-oxidized 304L : a) after deposition at room temperature; b) after 6 months of storage in air

The size of these aerosols is greater than those obtained by Tietze et al. [19] (16-105 nm) by the same technique, and the morphology is different. Indeed, the cage structure observed in this study seems to be due to the higher concentration $(240 \mathrm{~g} / \mathrm{L})$ of the aqueous CsI generating solution. On the other hand, aerosols obtained by vaporizing CsI and then cooling down the vapor in a cold gas flow, thus promoting the nucleation of aerosols, have a size of the order 1$3 \mu \mathrm{m}[10]$ [11] [20]. Moreover, ICP-MS analysis has revealed similar CsI amount among all the $304 \mathrm{~L}$ coupons of the same batch, with values ranging from 0.4 to $1.8 \mathrm{mg} / \mathrm{cm}^{2}$ of CsI from one experiment to another.

Whatever the chemical composition of the oxide layer, the XPS analysis of the CsI deposits on pre-oxidized $304 \mathrm{~L}$ reveals the detection of $\mathrm{Cs}$ and I in addition to the metal elements. This result is consistent with the SEM images which show that the micrometric aerosols do not completely cover the alloy substrate. XPS Cs $3 d$ and I 3d spectra of CsI aerosols deposited on pre-oxidized 304L under air are presented in Figure 4 and compared to those of crystalline CsI powder as reference. The XPS analysis of CsI shows in the Cs $3 \mathrm{~d}$ region the spin-orbit splitting of $\mathrm{Cs} 3 \mathrm{~d}_{5 / 2}(\mathrm{BE}=725.0 \mathrm{eV})$ and $\mathrm{Cs} 3 \mathrm{~d}_{3 / 2}(\mathrm{BE}=739.0 \mathrm{eV})$ besides additional satellite structures (SAT) at higher binding energies and in the I 3d region the spin-orbit splitting of I $3 \mathrm{~d}_{5 / 2}(\mathrm{BE}=619.4 \mathrm{eV})$ and $\mathrm{I} 3 \mathrm{~d}_{3 / 2}(\mathrm{BE}=630.8 \mathrm{eV})$. In order to achieve an atomic Cs/I ratio 
close to 1 for the analysis of CsI powder (99.9\%, Acros Organics), a Tougaard subtraction was performed taking into account only the areas of the main components Cs $3 d_{3 / 2}$ and I $3 d_{3 / 2}$ and their relative sensitive factors. Moreover, this methodology allows overcoming the interferences of $\mathrm{Cs} 3 \mathrm{~d}_{5 / 2}$ with the signal of Fe $2 \mathrm{p}$ and of I $3 d$ with Mn $2 \mathrm{p}$, respectively. Finally this approach allows obtaining an atomic Cs/I ratio of 1.1 for CsI aerosols deposited on preoxidized 304L confirming that CsI is deposited as CsI phase and its chemical composition is not modified by the deposition, as the BE are similar in both cases.
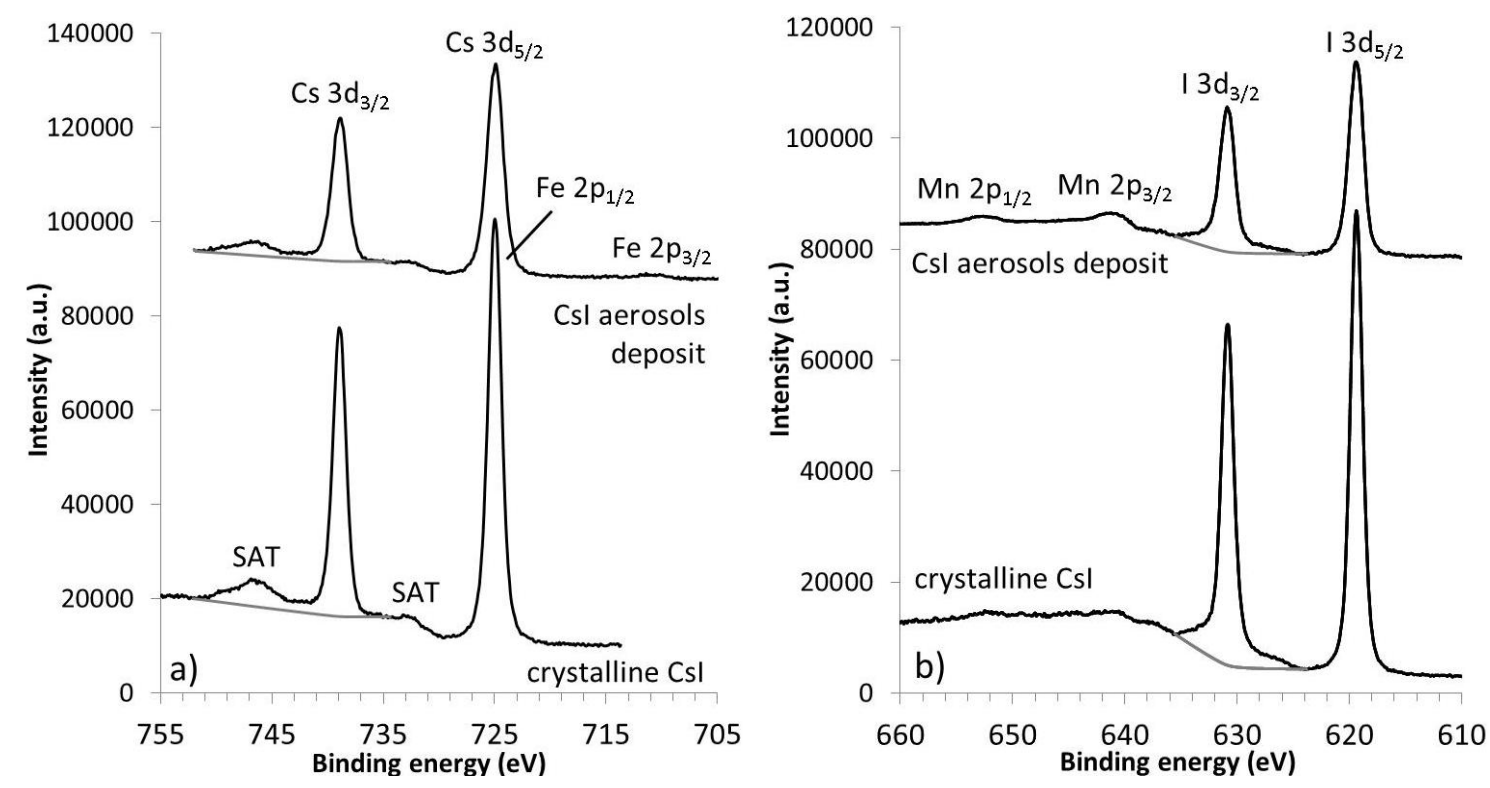

Figure 4: XPS a) Cs 3d and b) I 3d spectra of CsI aerosols deposited on pre-oxidized 304L under air and of crystalline CsI powder

\subsection{Re-vaporisation of CsI}

In order to investigate the parameters that influence the re-vaporisation of CsI deposits in terms of released and/or residual amount and chemical speciation, the samples were characterised after their heating until $750^{\circ} \mathrm{C}\left(5^{\circ} \mathrm{C} / \mathrm{min}-1 \mathrm{~h}\right)$ under different atmospheres featuring either air or steam. 


\subsubsection{Influence of the initial oxidized state}

First it has to be mentioned that whatever the initial oxidized state (air or steam pre-oxidation) and whatever the atmosphere of re-vaporisation (air or steam), iodine is not quantitatively detected by ICP-MS or by XPS, indicating an integral release of iodine species. Iodine has not been investigated in depth by ToF-SIMS since ionisation of this element occurs in negative mode while Cs is detected in positive mode. At the opposite, the residual amount of caesium obtained by ICP-MS analysis, in function of the atmospheres of pre-oxidation and revaporisation, is presented in Table 3. After air re-vaporisation, a residual amount of $20-28 \%$ of the initial Cs amount is found whatever the pre-oxidation atmosphere. After steam revaporisation, a residual amount of around $1 \%$ is detected whatever the pre-oxidation atmosphere, allowing to conclude an almost integral release of caesium species. It seems that the nature of the atmosphere during re-vaporisation is the key parameter in terms of residual amount of Cs.

\begin{tabular}{|c|c|c|c|}
\hline & \multicolumn{2}{|c|}{ Pre-oxidation atmosphere } \\
\hline & & Air & Steam \\
\hline \multirow{2}{*}{$\begin{array}{l}\text { Re- } \\
\text { vaporisation } \\
\text { atmosphere }\end{array}$} & Air & $26-28 \%$ & $20-24 \%$ \\
\hline & Steam & $0.6 \%$ & $1.2-1.4 \%$ \\
\hline
\end{tabular}

Table 3: Residual amount of Cs after re-vaporisation (\% with respect to the initial amount of Cs), as obtained by ICP-MS analysis

\subsubsection{Influence of the atmosphere of re-vaporisation}

\subsubsection{CsI re-vaporisation under air atmosphere}

Figure 5 presents the ToF-SIMS depth profiles of the coupons after air re-vaporisation from CsI deposited on air (Figure 5a) or steam (Figure 5b) pre-oxidized 304L. It can be clearly seen that caesium is detected decreasingly along the oxide thickness whatever its initial composition: $\mathrm{Cr}$ enrichment (air oxidation) or Mn enrichment (steam oxidation). Besides it seems that Cs diffuses into the alloy bulk in the case of air pre-oxidation whereas the Cs- 
profile nicely follows the Mn-profile until the interface with the alloy bulk in the case of steam pre-oxidation. The shape of the Cs-profile after air re-vaporisation could also be linked to the morphology of the surface itself, which is not well-defined presenting heterogeneities. Finally after the air re-vaporisation of CsI until $750^{\circ} \mathrm{C}$, on air pre-oxidized sample, the oxide layer is still composed of a mixture of mainly chromium and manganese. At the opposite, the surface composition obtained on steam pre-oxidized sample is significantly modified under air re-vaporisation conditions. Indeed, the outermost surface is no longer composed of only a thin Mn layer but the oxide layer is composed of a complex mixture of $\mathrm{Mn}, \mathrm{Cr}$ and $\mathrm{Fe}$. The profile of the $\mathrm{Fe}^{+}$ion fragment also varies in intensity with the depth, which has not been observed with the samples re-vaporized in steam.
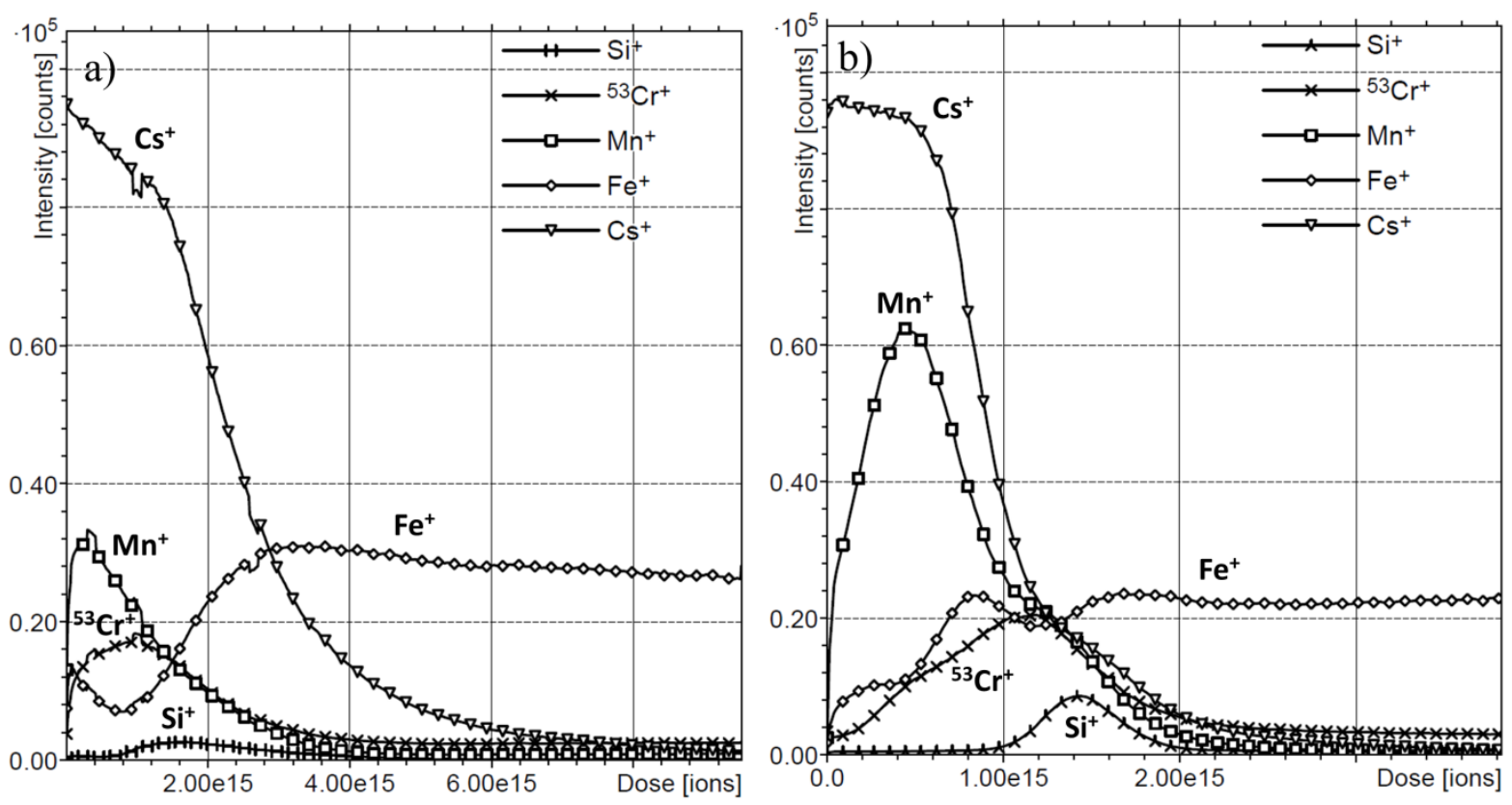

Figure 5: ToF-SIMS depth profiles of CsI deposited on $304 \mathrm{~L}$ oxidized at $750^{\circ} \mathrm{C}(24 \mathrm{~h})$ : a) under air and b) under steam atmospheres, after re-vaporisation under air atmosphere

This result is further confirmed by the XPS quantitative analysis presented in Table 4. Indeed, the atomic $\mathrm{Mn} / \mathrm{Cr}$ ratio of the air pre-oxidized sample is maintained at 0.4 after air re- 
vaporisation whereas the atomic $\mathrm{Mn} / \mathrm{Cr}$ ratio of the steam pre-oxidized sample is decreased from 10.6 to 0.4 after air re-vaporisation.

\begin{tabular}{|c|c|c|c|c|c|c|c|c|c|c|c|}
\hline \multirow{2}{*}{} & \multicolumn{10}{c|}{ Pre-oxidation atmosphere } \\
\cline { 3 - 12 } & \multicolumn{9}{|c|}{ Air } & \multicolumn{1}{c|}{ Steam } \\
\cline { 2 - 12 } & $\mathrm{Cs}$ & $\mathrm{Fe}$ & $\mathrm{Cr}$ & $\mathrm{Mn}$ & $\mathrm{Mn} / \mathrm{Cr}$ & $\mathrm{Cs}$ & $\mathrm{Fe}$ & $\mathrm{Cr}$ & $\mathrm{Mn}$ & $\mathrm{Mn} / \mathrm{Cr}$ \\
\hline $\begin{array}{c}\text { Re- } \\
\text { vaporisation } \\
\text { atmosphere }\end{array}$ & Air & 10.6 & 4.3 & 11.8 & 4.1 & 0.4 & 11.2 & 2.2 & 12.0 & 4.9 & 0.4 \\
\cline { 2 - 11 } & Steam & 3.3 & 1.3 & 15.4 & 6.4 & 0.4 & 1.8 & 1.7 & 1.9 & 19.0 & 10.0 \\
\hline
\end{tabular}

Table 4: XPS quantitative elemental composition $(\mathrm{Cs}, \mathrm{Fe}, \mathrm{Cr}$ and $\mathrm{Mn}$, atomic concentration $\%$ and atomic $\mathrm{Mn} / \mathrm{Cr}$ ratio) of CsI deposited on air or steam pre-oxidized 304L and revaporized under air or steam at $750^{\circ} \mathrm{C}$

Moreover, whatever the initial oxidized state, a new component appears on XPS Cr $2 p$ spectrum (Figure 6) at higher BE (579.5 eV) after air re-vaporisation, attributed to $\mathrm{Cr}^{6+}$ [17], besides the presence of $\mathrm{Cr}^{3+}$ as $\mathrm{Cr}_{2} \mathrm{O}_{3}$. The $\mathrm{Cr}^{6+}$ species represent approximately $50 \%$ of the total amount of chromium. Furthermore, it has to be noticed that an atomic ratio $\mathrm{Cs} / \mathrm{Cr}^{6+}$ of 1.9 is obtained, suggesting the formation of caesium chromates as $\mathrm{Cs}_{2} \mathrm{CrO}_{4}$.

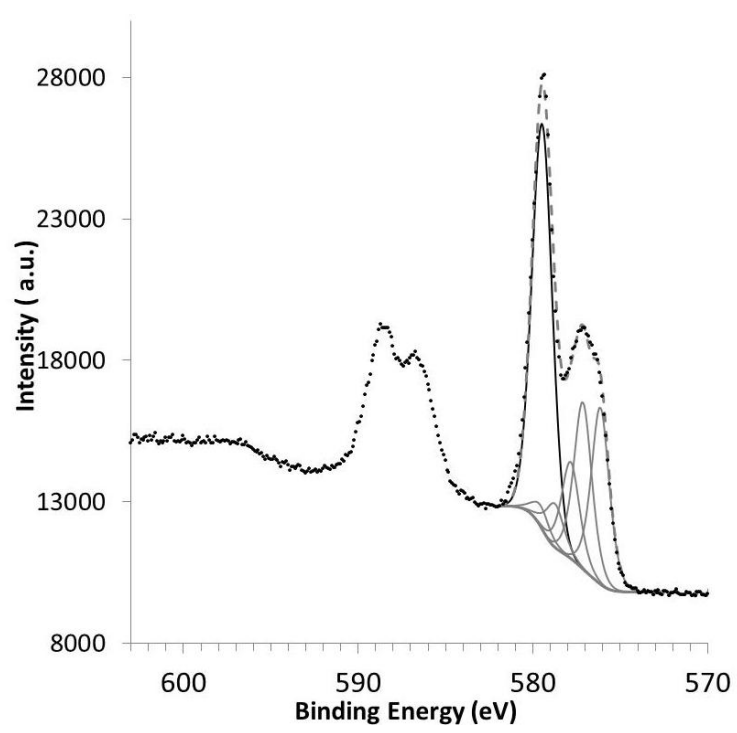

Figure 6: XPS Cr 2p spectrum of CsI deposited on steam pre-oxidized 304L and re-vaporized under air at $750^{\circ} \mathrm{C}$

Raman spectroscopy was used to further investigate the structure of the $\mathrm{Cr}^{6+}$ species. Figure 7 shows the spectra of yellow micrometric crystals that appear randomly on the surface (Figure 
8). By comparison with Raman spectra of other chromates and dichromates, the intense Raman lines in the range of $800-1000 \mathrm{~cm}^{-1}$ are attributed to $\mathrm{Cr}^{6+}$. Indeed, these lines have previously been assigned to $\mathrm{Cr}-\mathrm{O}$ stretching modes of the $\mathrm{CrO}_{4}$ group [21]. The most intense line at $842 \mathrm{~cm}^{-1}$ (Figure 7a) is attributed to the symmetric stretching vibration and lines at 863 , 870 and $885 \mathrm{~cm}^{-1}$ to the asymmetrical stretching modes. In the low frequency region, bending modes are located between 345 and $388 \mathrm{~cm}^{-1}$. The second Raman spectrum (Figure $7 \mathrm{~b}$ ) shows, besides the low intense spectral fingerprint of chromates, characteristic lines of the dimeric $\mathrm{Cr}^{6+}$ species $\left(\mathrm{Cr}_{2} \mathrm{O}_{7}{ }^{2-}\right)$ at $222,365,557$ and $906 \mathrm{~cm}^{-1}$ with in particular at $222 \mathrm{~cm}^{-1}$ the bending mode of the bridge, $\delta_{\mathrm{Cr}-\mathrm{O}-\mathrm{Cr}}$, that does not exist in monomeric $\left(\mathrm{CrO}_{4}{ }^{2-}\right)$ species.

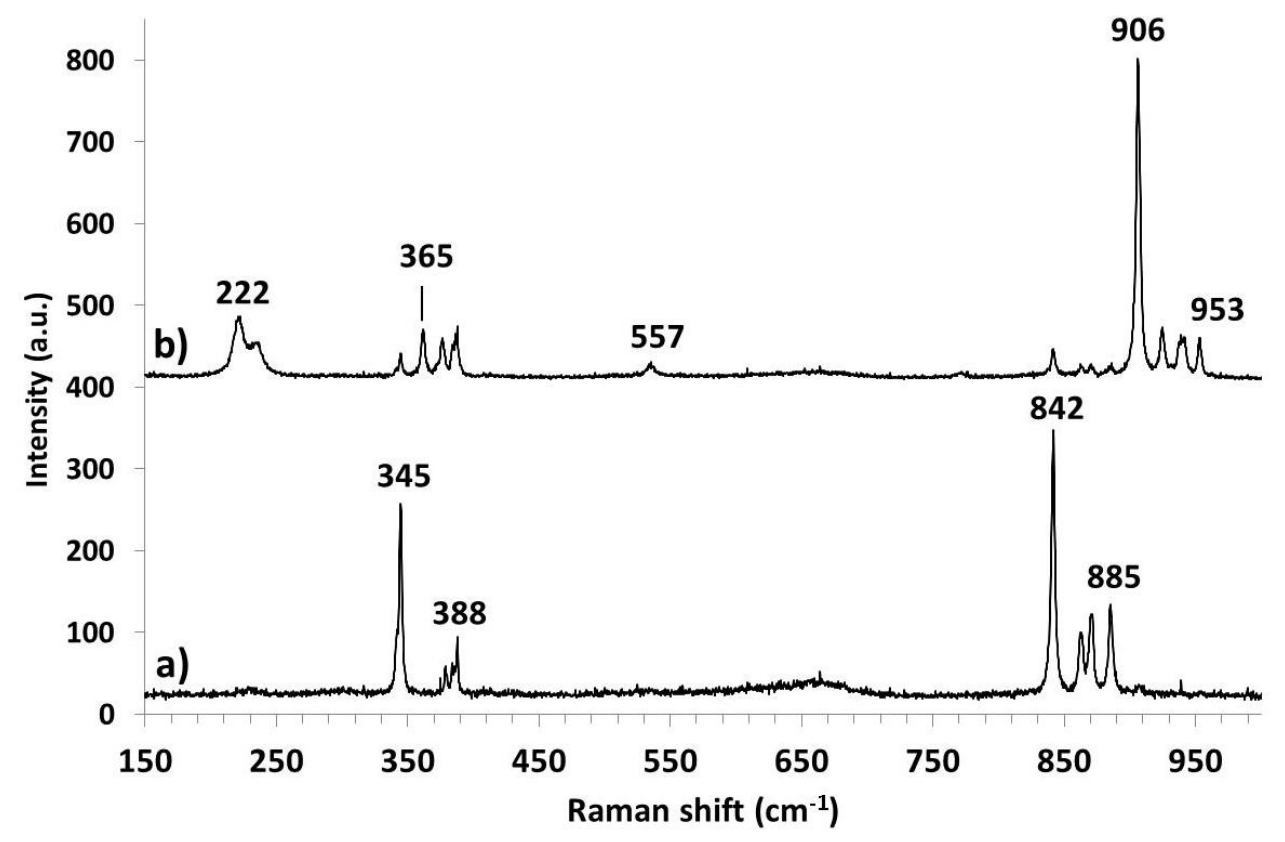

Figure 7: Raman spectra of a) caesium chromates and b) dichromates formed after the air revaporisation at $750^{\circ} \mathrm{C}$ of $\mathrm{CsI}$ from steam pre-oxidized $304 \mathrm{~L}$ 


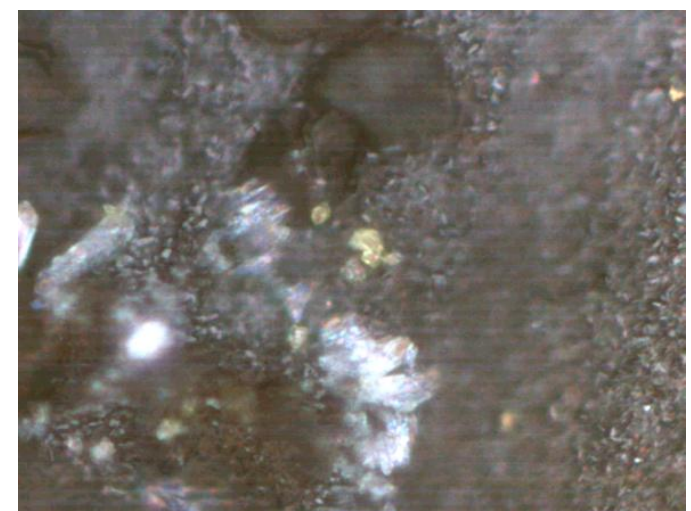

Figure 8: Optical image of the $\mathrm{Cs}_{2} \mathrm{Cr}_{2} \mathrm{O}_{7}$ grain (yellow crystal)

Finally, the formation of caesium chromates and dichromates is also confirmed by ToF-SIMS analysis in static conditions, providing molecular information characteristic of the outer monolayers. Indeed, two interesting positive mixed cluster ions were detected only after air re-vaporisation: $\mathrm{Cs}_{2} \mathrm{CrO}_{3}{ }^{+}(\mathrm{m} / z=365.7)$ and $\mathrm{Cs}_{2} \mathrm{Cr}_{2} \mathrm{O}_{9} \mathrm{H}^{+}(\mathrm{m} / z=514.7$, Figure 9a) revealing that various $\mathrm{Cr}$-containing fragments are bound with two $\mathrm{Cs}$ atoms and as a consequence confirming the formation of a Cr-Cs mixed oxide [22]. Moreover, a simulation of the isotopic pattern of the $\mathrm{Cs}_{2} \mathrm{Cr}_{2} \mathrm{O}_{9} \mathrm{H}^{+}$cluster, performed with the SurfaceLab software, has shown that the peak assignment is accurate (Figure 9b). 

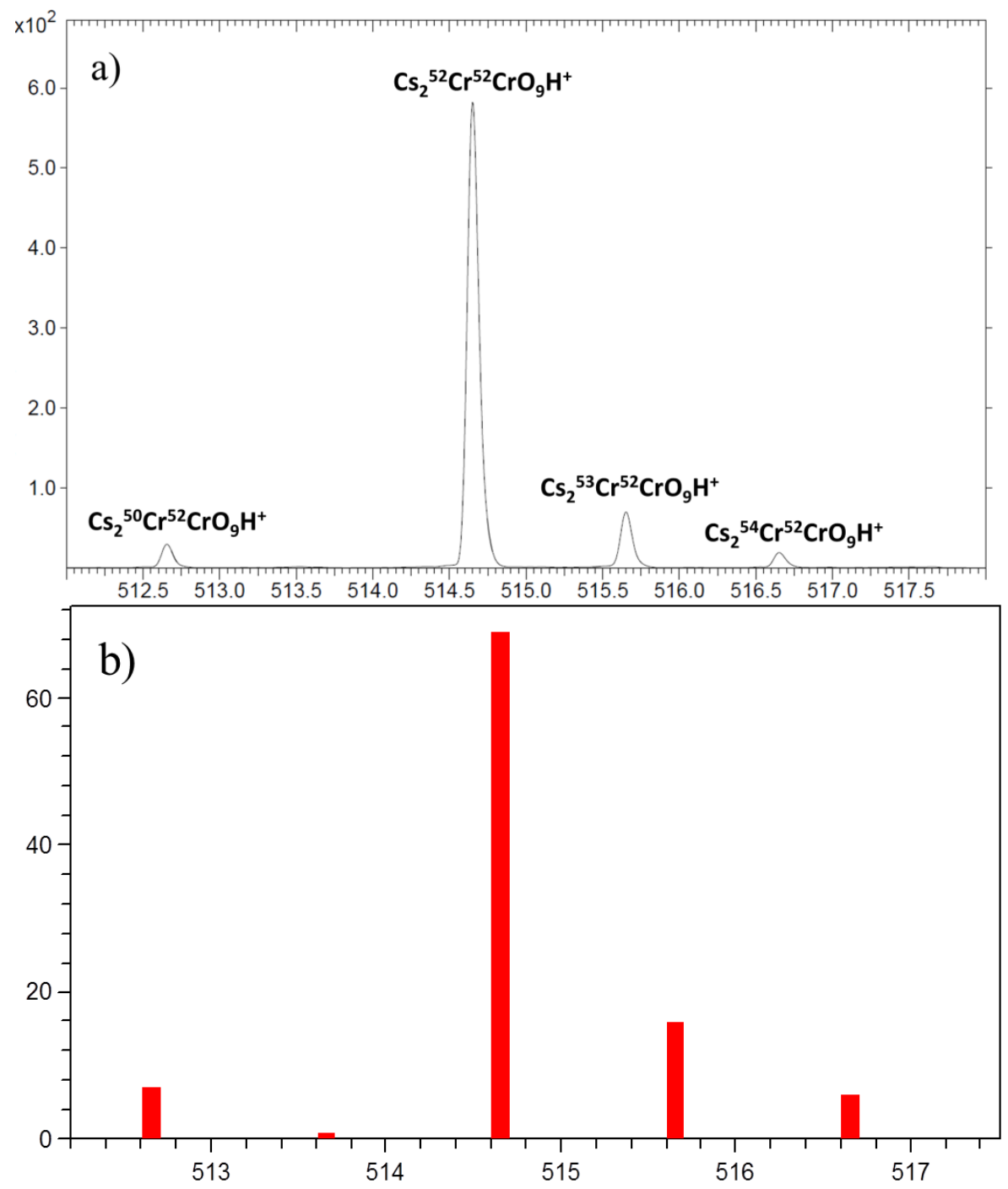

Figure 9: a) ToF-SIMS mass spectrum $(\mathrm{m} / \mathrm{z}=512-518)$ of CsI deposited on air or steam preoxidized $304 \mathrm{~L}$ and re-vaporized under air at $750^{\circ} \mathrm{C}$; b) Simulation of the isotopic pattern for $\mathrm{Cs}_{2} \mathrm{Cr}_{2} \mathrm{O}_{9} \mathrm{H}^{+}$, as calculated by the SurfaceLab software

\subsubsection{CsI re-vaporisation under steam atmosphere}

Figure 10 presents the ToF-SIMS depth profile of the sample after steam re-vaporisation from CsI deposited on steam pre-oxidized 304L. It can be clearly seen that caesium is detected at the outer surface then its signal decreases rapidly, revealing a thin layer of Mn followed by a thicker layer of Cr. This double oxide layers structure was previously observed after the oxidizing pre-treatment under steam, suggesting that the almost complete re-vaporisation of caesium species does not modify the structure and composition of the initial oxidized state. 
These observations are correlated with the XPS quantitative analysis (Table 4). Indeed, a low amount of Cs is detected (around 2 at. \%) and no chemical modification is observed on $\mathrm{Cr} 2 \mathrm{p}$ $\left(\mathrm{Cr}_{2} \mathrm{O}_{3}\right)$ nor $\mathrm{Mn} 2 \mathrm{p}$ (mixture of $\mathrm{Mn}_{2} \mathrm{O}_{3} / \mathrm{MnO}$ ). It has to be finally mentioned that no Cs-Cr mixed fragments were detected by ToF-SIMS.

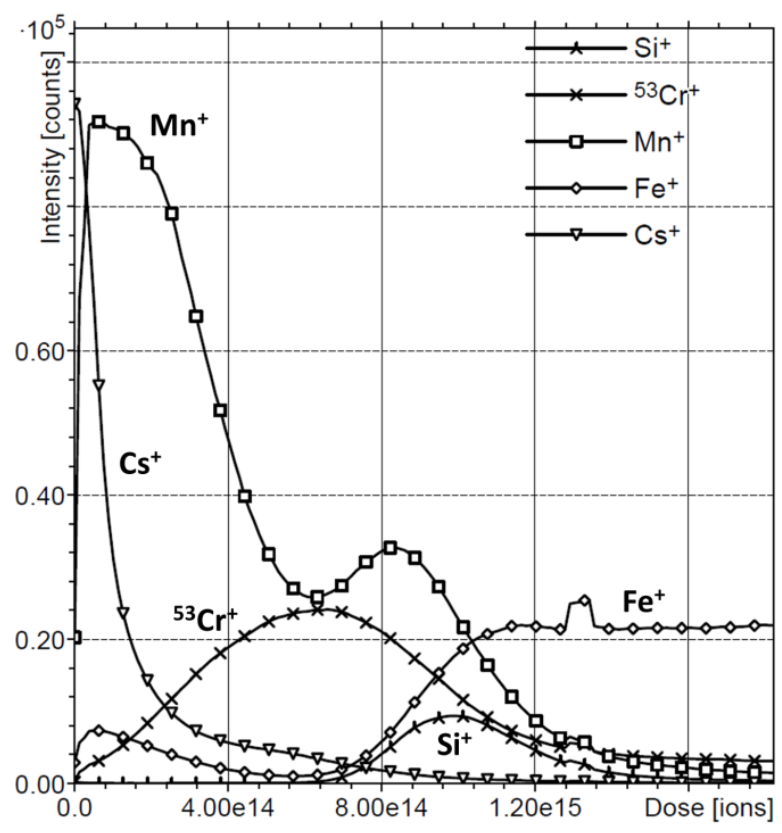

Figure 10: ToF-SIMS depth profile of $304 \mathrm{~L}$ oxidized at $750^{\circ} \mathrm{C}(24 \mathrm{~h})$ under steam atmosphere and re-vaporized under steam atmosphere

\section{Discussion}

The results of the combined XPS and ToF-SIMS surface analyses of the re-vaporisation of CsI aerosols deposited on oxidized 304L coupons allowed obtaining several important pieces of information. First of all, the initial surface state of the oxidized 304L coupon is strongly dependent on the oxidizing conditions. As such, in air atmosphere the oxide has a single-layer structure (based on ToF-SIMS observation) composed mainly of chromium (identified as $\mathrm{Cr}_{2} \mathrm{O}_{3}$ by XPS) and a small amount of manganese $(\mathrm{MnO})$. On the contrary, during oxidation in argon/steam atmosphere the oxide has a dual-layer structure: a thin surface layer rich in 
manganese $\left(\mathrm{MnO} / \mathrm{Mn}_{2} \mathrm{O}_{3}\right)$ and a second layer rich in chromium $\left(\mathrm{Cr}_{2} \mathrm{O}_{3}\right)$. These results are consistent with previous studies in the same temperature range [12].

With regard to CsI re-vaporisation, post-experimental ICP-MS and quantitative XPS analyses have shown no influence of the pre-oxidized 304L surface state on the amount of released/residual caesium and iodine. It is worth noting that the surface state of a coupon preoxidized in argon/steam and re-vaporized in air suffers modifications. Particularly, the double-layer oxide structure disappears and the surface is composed mainly of $\mathrm{Cr}_{2} \mathrm{O}_{3}$ and a small amount of $\mathrm{MnO}$, which corresponds to the initial surface state after pre-oxidation in air. The surface state of other coupons i.e. firstly oxidized in air and then re-vaporized in air or argon/steam or firstly oxidized in argon/steam and re-vaporized in argon/steam did not undergo any major modifications. This suggests that the final surface state of a 304L stainless steel coupon is determined by the air atmosphere during either the oxidation or revaporisation phase.

On the contrary, the composition of the carrier gas has been observed to influence significantly the release of caesium iodide. Specifically, during re-vaporisation in argon/steam caesium and iodine are released integrally from the surface of the 304L coupon, whereas in air atmosphere a non-negligible amount of caesium is retained on the surface (up to $30 \%$ from the initial Cs deposit), while the iodine is integrally released. Also, during air re-vaporisation, XPS analysis has revealed the emergence of another $\mathrm{Cr}$ component, at higher binding energy (579.5 eV) corresponding to the +6 oxidation state of chromium $\left(\mathrm{Cr}^{6+}\right)$. Despite the harsh conditions, $\mathrm{Cr}^{6+}$ species were not observed after the air pre-oxidation phase. This suggests the dissociation of the CsI molecule which leads to the formation of a $\mathrm{Cs}-\mathrm{Cr}$ mixed oxide and an unknown iodine containing species. Previous studies have discussed the formation of such kind of compounds: $\mathrm{Cs}_{2} \mathrm{CrO}_{4}, \mathrm{Cs}_{2} \mathrm{Cr}_{2} \mathrm{O}_{7}, \mathrm{Cs}_{3} \mathrm{CrO}_{4}$ and $\mathrm{Cs}_{4} \mathrm{CrO}_{4}$ [4] [23]. Furthermore, the analysis of the mass spectrum obtained by ToF-SIMS has revealed the presence of a mixed 
fragment at $m / z=365.7$ which can be attributed to the cluster $\mathrm{Cs}_{2} \mathrm{CrO}_{3}{ }^{+}$. Another mixed fragment has been detected at $m / z=514.7$, which corresponds to $\mathrm{Cs}_{2} \mathrm{Cr}_{2} \mathrm{O}_{9} \mathrm{H}^{+}$. The relative intensity of this peak with respect to three others with close masses $(-2,+1$ and +2$)$ represents the isotopic signature of a fragment containing two chromium atoms. In fact, natural chromium contains several stable isotopes $\left({ }^{50} \mathrm{Cr},{ }^{52} \mathrm{Cr},{ }^{53} \mathrm{Cr},{ }^{54} \mathrm{Cr}\right)$ and the intensity of the peaks is related to the natural abundance of said isotopes. For instance, the most intense peak corresponds to an ion fragment containing two ${ }^{52} \mathrm{Cr}$ atoms (the most abundant isotope of natural chromium, 83.8\%). Moreover, the depth profiles of $\mathrm{Cs}_{2} \mathrm{CrO}_{3}{ }^{+}$and $\mathrm{Cs}_{2} \mathrm{Cr}_{2} \mathrm{O}_{9} \mathrm{H}^{+}$ion fragments follow the same evolution as the $\mathrm{Cs}^{+}$and the $\mathrm{Cs}_{2} \mathrm{O}^{+}$ion fragments, which strongly indicates that $\mathrm{Cs}_{2} \mathrm{CrO}_{4}$ and $\mathrm{Cs}_{2} \mathrm{Cr}_{2} \mathrm{O}_{7}$ have been formed following the interaction between caesium and chromium at high temperature in the presence of air. It has to be noted that these compounds have not been observed after re-vaporisation in presence of steam, that is to say no $\mathrm{Cr}^{6+}$ component has been detected by XPS analysis and no $\mathrm{Cs}_{2} \mathrm{CrO}_{3}{ }^{+}$or $\mathrm{Cs}_{2} \mathrm{Cr}_{2} \mathrm{O}_{9} \mathrm{H}^{+}$ion fragments have been observed by ToF-SIMS. Finally, the Cs-Cr mixed oxides structure has been confirmed by Raman analysis.

The formation of Cs-Si compounds, which has been reported by Elrick et al. [2] and Di Lemma et al. [5] [24] has not been observed during this study. The depth profile of the $\mathrm{Si}^{+}$ion fragment obtained by ToF-SIMS analysis has revealed the fixing of silicon at the interface between the oxide layer and the bulk material, which is consistent with previous studies [2] [3] [6]. However, no correlation has been observed between the $\mathrm{Si}^{+}$and $\mathrm{Cs}^{+}$depth profiles. There are several possible explanations. As such, Elrick et al. [2] and Sallach et al. [3], who conducted research with both $\mathrm{CsI}$ and $\mathrm{CsOH}$, argue that $\mathrm{CsI}$ is more stable and thus less susceptible to dissociate and form Cs-Si compounds. Also, the experimental parameters in the experiments conducted by Elrick et al. [2] and Di Lemma et al. [5] [24] are different from the ones used in this study. Specifically, the heating is carried out to a higher temperature (up to 
$1000^{\circ} \mathrm{C}$ [5] [24] and $1100^{\circ} \mathrm{C}$ [2] [3]). Since the diffusion of Cs through the oxide layer seems to show Arrhenius-type temperature dependence [6], it is likely that a higher temperature allows a deeper penetration of Cs through the oxide layer and its fixation in the Si-rich layer, with the subsequent formation of Cs-Si compounds.

\section{Conclusion}

This study was focused on the interaction between fission product deposits (CsI) and primary piping system model surface, identified as oxidized 304L stainless steel, during the remobilization phenomenon that can occur in PWR during a severe nuclear accident. The study was carried over a range of experimental parameters, namely the initial surface state of the 304L stainless steel and the composition of the carrier gas during re-vaporisation. The results can have an impact on the assessment of the quantity of radioactive material that can be eventually released in case of a severe accident. As such, it has been concluded that:

- Iodine is released integrally regardless of the conditions, probably a part under volatile species ;

- The initial surface state of the 304L stainless steel substrate (pre-oxidation in air vs steam) does not play any significant role on the amount of released caesium, nor does influence the final surface state;

- The composition of the carrier gas during re-vaporisation influences significantly the release of Cs: under steam $\mathrm{Cs}$ is released integrally and the surface state remains unchanged after re-vaporisation, whereas in air a non-negligible quantity of Cs (20$30 \%$ of the initial Cs amount) is retained on the surface of the oxidized 304L stainless steel and forms mixed compounds with chromium oxide, such as $\mathrm{Cs}_{2} \mathrm{CrO}_{4}$ and $\mathrm{Cs}_{2} \mathrm{Cr}_{2} \mathrm{O}_{7}$. 
Further studies should take into account such factors as the nature of the CsI deposit (vapour condensation and thermophoresis as opposed to aerosol deposit) as well as the nature of released caesium and iodine. Also, it is worth investigating the mechanisms which lead to the retention of $\mathrm{Cs}$ on the surface and the formation of $\mathrm{Cs}-\mathrm{Cr}-\mathrm{O}$ compounds in the particular case of re-vaporisation in presence of air.

\section{Acknowledgements}

This work has been supported by the French State under the program "Investissements d'Avenir" MiRE managed by the ANR under Grant Agreement No. ANR-11-RSNR-0013-01 and the Fonds Européen de Développement Régional (FEDER), CNRS, Région Nord Pas-deCalais and Ministère de l'Education Nationale de l'Enseignement Supérieur et de la Recherche are acknowledged for fundings of XPS/LEIS/ToF-SIMS spectrometers within the Pôle Régional d'Analyses de Surface. Dr. E. Berrier is gratefully acknowledged for the Raman spectroscopy analyses. 


\section{References}

[1] Haste, T. and Payot, F., Transport and deposition in the Phébus FP circuit, Annals of Nuclear Energy 61, 102-121 (2013).

[2] Elrick, R.M., Sallach, R.A., Ouellette, A.L., Douglas, S.C. Reaction Between Some Cesium-Iodine Compounds and the Reactor Materials 304 Stainless Steel, Inconel 600 and Silver; Volume I Cesium Hydroxide Reactions, Sandia National Laboratories, NUREG/CR$3197 / 1$ of 3 (1984).

[3] Sallach, R.A., Elrick, R.M., Douglas, S.C., Ouellette, A.L. Reaction Between Some Cesium-Iodine Compounds and the Reactor Materials 304 Stainless Steel, Inconel 600 and Silver; Volume II: Cesium Iodide Reactions, Sandia National Laboratories, NUREG/CR$3197 / 2$ of 3 (1986).

[4] Sasaki, K., Tanigaki, T., Oshima, Tomohiro, Fukumoto, K., Masayoshi, U., Microstructure analysis for chemical interaction between cesium and SUS316 steel in fast breeder reactor application, Journal of Energy and Power Engineering, 7 716-725 (2013).

[5] Di Lemma, F.G, Nakajima, K., Yamashita, S., Osaka, M., Experimental investigation of the influence Mo contained in stainless steel on Cs chemisorption behavior, Journal of Nuclear Materials, 484 174-182 (2017).

[6] Allen, G.C., Bowsher, B.R., Dickinson, S., Fotios, G.M., Nichols, A.L., Wild, R.K., Surface studies of the interaction of cesium hydroxide vapor with 304 stainless steel, Oxidation of Metals, Vol. 28, Nos. 1/2 (1987)

[7] Bottomley, P.D.W., Knebel K., Van Winckel, S., Haste ,T., Souvi , S.M.O., Auvinen , A., Kalilainen , J., Kärkelä, T. Revaporisation of fission product deposits in the primary circuit and its impact on accident source term, Annals of Nuclear Energy, 74 208-223 (2014). 
[8] Knebel, K., Bottomley, P.D.W., Rondinella, V.V., Auvinen, A, Jokiniemi, J. An experimental device to study the revaporisation behavior of fission product deposits under severe accident conditions, Progress in Nuclear Energy, 72 77-82 (2014).

[9] Allen, T., et al., Materials challenges for nuclear systems, Materials Today, 2010, vol 13, $\mathrm{n}^{\circ} 12$, ISSN: 13697021

[10] Shibazaki, H., et al., Revaporization of a CsI aerosol in a horizontal straight pipe in a severe accident condition, Nuclear Technology, 2001, vol. 134, p. 62-70.

[11] Maruyama, Y., et al., Vapor Condensation and Thermophoretic Aerosol Deposition of Cesium Iodide in Horizontal Thermal Gradient Pipes, Journal of Nuclear Science and Technology, 1999, vol. 36, p. 433-442.

[12] Mamede, A.-S., Nuns, N., Cristol, A.-L., Cantrel, L., Souvi, S., Cristol, S., Paul, J.-F., Multitechnique characterization of 304L surface states oxidized at high temperature in steam and air atmospheres, Applied Surface Science, 369 510-519 (2016)

[13] Da Cunha Belo, M., Walls, M., Hakiki, N.E., Corset, J., Picquenard, E., Sagon, G., Noël, D., Composition, structure and properties of the oxide films formed on the stainless steel 316L in a primary type PWR environment, Corrosion Science, 40 447-463 (1998)

[14] Auvinen, A., Brillant, G., Davidovich, N., Dickson, R., Ducros, G., Dutheillet, Y., Giordano, P., Kunstar, M., Kärkelä, T., Madlin, M., Pontillon, Y., Séropian, C., Vér, N., Progress on ruthenium release and transport under air ingress conditions, Nuclear Engineering and Design 238 3418-3428 (2008)

[15] Neil Fairley, www.casaxps.com

[16] Shirley, D.A., High-Resolution X-Ray Photoemission Spectrum of the Valence Bands of Gold, Phys. Rev. B, 1972, vol. 5, p. 4709-4714. 
[17] Biesinger, M.C., et al., Resolving surface chemical states in XPS analysis of first row transition metals, oxides and hydroxides: Cr, Mn, Fe, Co and Ni, Applied Surface Science, 2011, vol. 257, n 7 , p. 2717-2730.

[18] Riggs, C.A., et al., Water adsorption isotherms for charged and uncharged cesium iodine aerosol particles, Nuclear Technology, 2007, vol. 157, issue 1, p. 74-86

[19] Tietze, S., et al., Adsorbtion and revaporisation studies of thin iodine oxide and CsI aerosols deposits from containment surface materials in LWRs, NKS-285, ISBN 97887-7893-360-7, 2013.

[20] Hidaka, A., et al., Experimental and Analytical Study of the Behavior of Caesium Iodide Aerosol/Vapor Deposition onto Inner Surface of Pipe Wall under Severe Accident Conditions, Journal of Nuclear Science and Technology, 1995, vol. 32, p. $1047-1053$

[21] Ramsey, J.D., et al., Raman spectroscopic analysis of the speciation of dilute chromate solutions, Corrosion Science, 2001, vol. 43, p. 1557-1572

[22] Weng, L.-T., Advances in the surface characterization of heterogeneous catalysts using ToF-SIMS, Applied Catalysis A: General, 2014, vol. 474, p. 203-210

[23] Antill, J.E., et al., Corrosion of stainless steel in the presence of caesium, Journal of Nuclear Materials, 1975, vol. 56, p. 47-60

[24] Di Lemma, F.D., et al., Surface analyses of cesium hydroxide chemisorbed onto type 304 stainless steel, Nuclear Engineering and Design, 2016, vol. 305, p. 411-420 